\title{
Effect of anaesthesia on intraocular blood flow
}

\author{
Rosemary Robinson, Mary White, Patrick McCann, John Magner, Peter Eustace
}

\begin{abstract}
Pulsatile ocular blood flow, intraocular pressure, systemic blood pressure, and heart rate was measured in two groups of 15 patients. One received lignocaine $1.5 \mathrm{mg} / \mathrm{kg}$ intravenously prior to induction. There was a significant increase in intraocular pressure after suxamethonium, which was not associated with any rise in ocular blood flow. Both the IOP and ocular blood flow increased significantly after tracheal intubation. $A$ rise in ocular blood flow reflects the stress response associated with intubation. Lignocaine failed to attenuate either response.
\end{abstract}

Laryngoscopy and endotracheal intubation can cause an increase in both intracranial and intraocular pressure (IOP). ${ }^{12}$ Suxamethonium has also been associated with an increase in IOP. ${ }^{3}$ The mechanism by which this is brought about is uncertain. Murphy et $\mathrm{al}^{4}$ showed that the major increase in IOP occurs immediately after endotracheal intubation rather than after the intravenous administration of suxamethonium. As a direct continuation of this study we examined the effect of administration of suxamethonium and endotracheal intubation on ocular blood flow to study the cause of these findings.

Intraocular pressure and pulsatile ocular blood flow (OBF) were measured by the Langham OBF System. ${ }^{5}$ Briefly, this instrument is based on the principle that blood flow to the eye is pulsatile. With each heart beat a bolus of blood is pumped into the eye which alters the intraocular pressure. From previously calculated pressure volume curves the change in pressure can be converted to a known volume. When multiplied by the heart rate per minute, the pulsatile flow to the eye per minute can be calculated. The IOP is measured with a sensitive electronic pneumatonometer which can record IOP at $30 \mathrm{~ms}$ intervals, giving a total of 30 pressure readings during each IOP pulsation. Thus our accurate and reproducible recording of systolic and diastolic IOP is recorded and the change in IOP can be easily measured.

\section{Materials and methods}

Thirty patients giving informed consent and undergoing general anaesthesia, requiring intubation, for elective surgery were studied pros-

University College, Dublin

P McCann

P Eustace

Correspondence to: Professor P Eustace, Department of Ophthalmology, Mater Misericordiae Hospital Dublin 7, Ireland.

Accepted for publication 2 August 1990

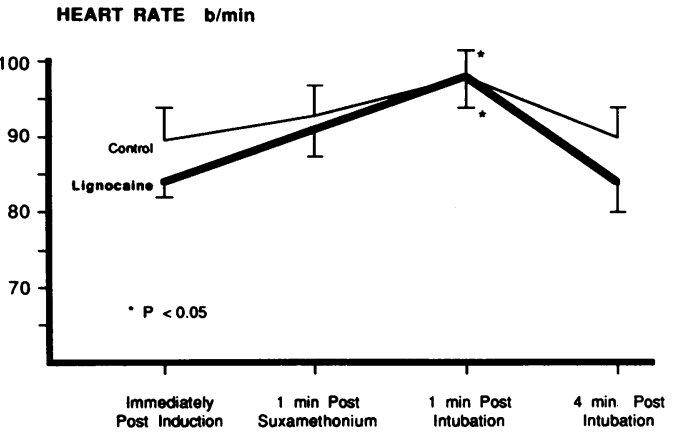

Figure 1 There is a significant increase one minute after intubation. b/min = beats per minute.

pectively. All patients were American Society of Anesthesiologists groups $1 / 11 .^{6}$ Patients with a history of glaucoma, cataract, hypertension, diabetes, or carotid artery disease were excluded from the study. They were grouped by random number allocation into two groups of 15 on a double blind basis. Group 1 received intravenous lignocaine $1.5 \mathrm{mg} / \mathrm{kg}$ pretreatment one minute before induction, while group 2 received a placebo of $10 \mathrm{ml}$ of saline.

All received diazepam $10 \mathrm{mg}$ orally one hour prior to surgery. All were induced with a sleep dose of thiopentone $4-5 \mathrm{mg} / \mathrm{kg}$, followed by suxamethonium $1.5 \mathrm{mg} / \mathrm{kg}$ one minute later, followed by endotracheal intubation one minute later. They were then maintained on a mixture of oxygen and nitrous oxide and enfluorane.

The IOP and OBF were measured by the Langham OBF System, and the heart rate and mean blood pressure were measured simultaneously with a Dynamap. Measurements were taken immediately after induction at loss of the eyelash reflex, one minute after suxamethonium just prior to laryngoscopy, one minute after tracheal intubation, and four minutes later. The results were analysed by Student's $t$ test for continuous variables.

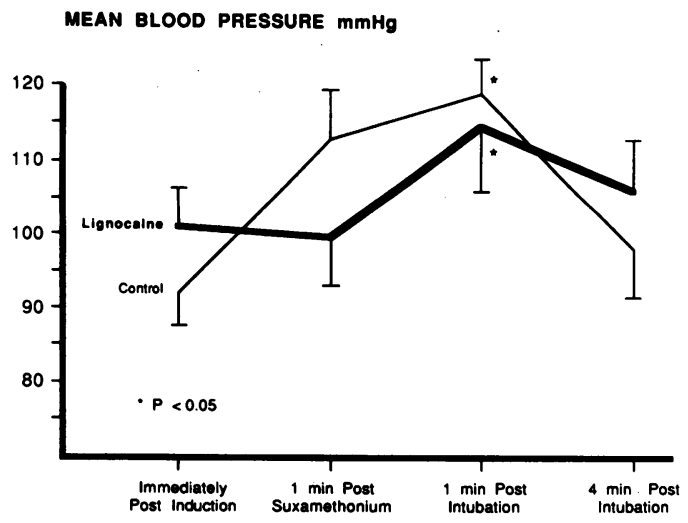

Figure 2 There is a significant increase one minute after intubation. There is no significant difference between the two groups at any stage. 
INTRAOCULAR PRESSURE mmHg

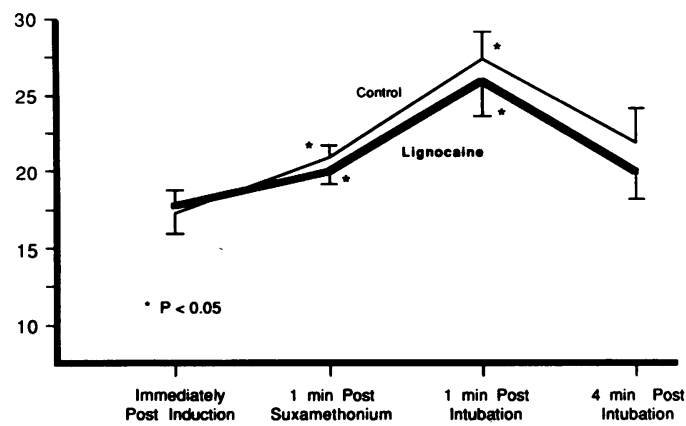

Figure 3 There is a significant increase one minute after suxamethonium and a further significant increase one minute after intubation.

\section{Results}

Both groups were evenly matched for age, sex, and weight (Table 1). There was no significant difference in heart rate and mean blood pressure between group 1 and group 2 at any time (Figs 1, 2). Both parameters showed a significant increase from baseline one minute after endotracheal intubation $(\mathrm{p}<0.05)$.

The ocular haemodynamics are shown in Figures 3 and 4. There was a significant decrease in $\mathrm{OBF}$ in the control group immediately after suxamethonium $(\mathrm{p}<0.05)$. Flow in the lignocaine group, however, remained at postinduction levels. There was a significant increase in IOP $(p<0.05)$ in both groups at this time. After intubation there was an even greater rise in IOP associated with a significant increase in OBF $(\mathrm{p}<0.05)$ in both groups. All 4 parameters returned to baseline 4 minutes after intubation.

\section{Discussion}

Poulton and James ${ }^{7}$ demonstrated that the cough reflex in awake subjects is suppressed by lignocaine $1.5 \mathrm{mg} / \mathrm{kg}$. Donegan and Bedford ${ }^{1}$ also showed that lignocaine reduced the increase in intracranial pressure associated with tracheal suction in comatose patients. Drenger and $\mathrm{Pe}^{\prime} \mathrm{er}^{2}$ reduced the increase in IOP after tracheal intubation by intravenous lignocaine. Murphy et $a l,{ }^{4}$ however, have shown that lignocaine $1.5 \mathrm{mg} / \mathrm{kg}$ does not prevent the rise in IOP seen after administration of suxamethonium and tracheal intubation. Our results agree with this study, as lignocaine did not appear to alter any of the parameters measured in either group.

It is uncertain how suxamethonium increases IOP. Some workers believe it is due to sustained contraction of the extraocular muscles. ${ }^{8}$ Hess and Pilar ${ }^{9}$ demonstrated two types of muscle fibres in the extraocular muscle of the cat. The Felderstruktur respond with a slow tonic contraction when exposed to acetylcholine or depolarising relaxants. The Fibrillenstruktur, in
INTRAOCULAR BLOOD FLOW $\mu 1 / \mathrm{min}$

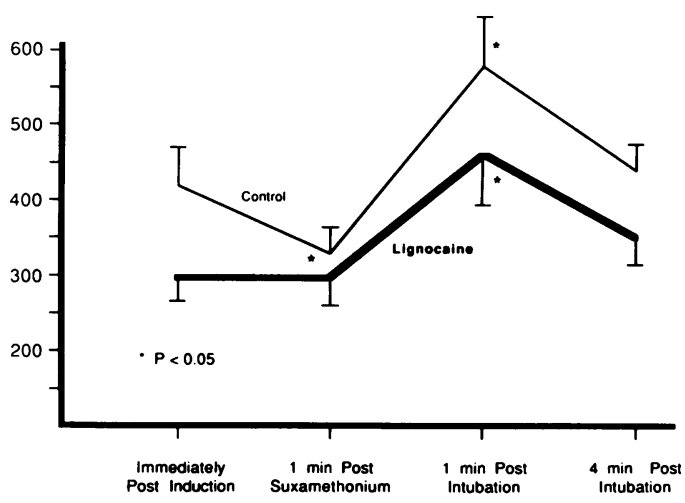

Figure 4 There is a significant decrease in the control group one minute after suxamethonium. Both groups show a significant increase one minute after intubation.

contrast, respond with a twitch response. The former predominate, and it is proposed that sustained contraction puts increased tension on the globe and thereby increases IOP. However, administration of D-tubocurare, which should counteract the depolarising action of suxamethonium, does not alter its effect on IOP. ${ }^{10}$ Adams and Barnett " have proposed that the increase in IOP is due to choroidal vasodilatation. Our study shows no increase in ocular blood flow after intravenous administration of suxamethonium. Therefore the controversy persists.

After intubation there is an increase in heart rate and blood pressure. This reflects the stress response associated with tracheal intubation. As the eye is an essential organ, this is associated with increased blood flow to this area and thus an increase in IOP.

In conclusion, the major increase in intraocular pressure occurs owing to increased blood flow to the eye as part of the stress response of endotracheal intubation.

1 Donegan MF, Bedford RF. Intravenously administered lidocaine prevents intracranial hypertension during endotracheal suctioning. Anesthesiology 1980; 52: 516-8.

2 Drenger B, Pe'er J. Attenuation of ocular and systemic responses to tracheal intubation by intravenous lignocaine. Br $\mathcal{F}$ Ophthalmol 1987; 71: 546-8.

3 Cook JH. The effect of suxamethonium on intraocular pressure. Anaesthesia 1981; 70: 359-65.

4 Murphy DF, Eustace P, Unwin A, Magner JB. Intravenous lignocaine pretreatment to prevent IOP rise following suxamethonium and tracheal intubation. Br $\mathcal{F}$ Ophthalmol 1986; 70: 596-8.

5 Langham ME, Farrell R, O'Brien V, Silver D, Schilder P. Blood flow in the human eye. Acta Ophthalmol (Kbh) 1989; Blood flow in the human eye. Acta Ophthalmol (Kbh) 1989;

6 American Society of Anesthesiologists. New classification of physical status. Anesthesiology 1963; 24: 111

7 Poulton TJ, James FM. Cough suppression by lidocaine. Anesthesiology 1979; 50: 470-2.

8 Lincoff HA. The effect of succinylcholine on intraocula pressure. Am F Ophthalmol 1955; 40: 501-10.

9 Hess A, Pilar G. Slow fibres in the extraocular muscles of the cat. F P hysiol (Lond) 1963; 169: 780-98.

10 Meyers EF, Krupin T, Johnson M, Zink H. Failure of nondepolarizing neuromuscular blockers to inhibit succinylcholine induced increased intraocular pressure: a controlled study. Anesthesiology. 1978; 48: 149-51.

11 Adams AK, Barnett KC. Anaesthesia and intraocular pressure. Anaesthesia 1966; 21: 202-10. 